\title{
Awareness of Nutrition among School Students through Media
}

\author{
Leo Gertrude ${ }^{a}$, Dr. Muthukumar ${ }^{\mathrm{b}}$, Dr.N. Tamilselvi ${ }^{\mathrm{c}}$ \\ aAssistant Professor, Department of Visual Communication, Kumaraguru College of Liberal Arts and Science, \\ Coimbatore. E-mail: leogertrude@gmail.com \\ ${ }^{\mathrm{b}}$ Assistant Professor, Department of Biotechnology, School of Biotechnology and Health Sciences, Karunya \\ University, Coimbatore. E-mail: muthukumar@karunya.edu \\ ${ }^{c}$ HOD, Visual Communication, The QuaideMilleth College for Men, Medavakam, Chennai. \\ E-mail: tamiselvishahul@gmail.com
}

Article History: Received: 11 January 2021; Accepted: 27 February 2021; Published online: 5 April 2021

\begin{abstract}
To lead a healthy lifestyle it is important to have sufficient knowledge on nutrition its importance in our daily lives. It is also essential to have this awareness at a younger age so that healthy eating becomes a habit and eventually a lifestyle. To have a clear understanding of what the food we eat contains or the nutrients present in them, it is essential to give nutritional awareness in foods in relation to their performance in the maintaining the body with stamina, help in growth and repair of worn out tissues and also to improve the body's immunity. This conceptual paper aims to find out the awareness of nutritional knowledge given through media and its effectiveness among students of high school with extensive review of literature.
\end{abstract}

Keywords: Nutritional Awareness, Eating Habits, Media and Nutrition, School Children, Healthy Lifestyle.

\section{Objective}

This study aims to review the awareness of nutrition among high school students through media under the following heads.

1. The importance of proper nutritional awareness among students in high school.

2. The role of media and its effectiveness in creating nutritional awareness among school students.

3. Perception of individual students about food advertisements presented in media.

4. Ways in which media can create nutritional awareness among school students.

\section{The Importance of Proper Nutritional Awareness among School Going Children}

Nutritional deficiencies, under nutrition, diet-related chronic diseases, and obesity are all problems of the modern society that exist side by side. This can result in inadequate physical and mental development, harmful diseases, and devastating fatalities, and also to a heavy loss of human potential, economic and social development (McNulty, 2013). To prevent the emergence of a pressing economic and social burden in the future, countries should focus on educating their people about eating the right foods (FAO, 2011).In India, where there are people at both the ends of the nutritional spectrum, nutritional awareness has become the need of the hour, especially among school students.

R.V. Bhavani, project director of the B.V. Rao Center for Sustainable Food Security, has stated that Junk food has entered the market, and urban school children and the middle class are more open to these kinds of foods. On one side we have this huge population of hunger and malnourished children, but the manifestations of the problem of obesity and related issues are also surfacing. These foods are finding their way even to rural areas at a faster pace, so unless there is more awareness of the right kinds of food to consume, we are going to have problems (Abler, 2008).

The health care sector in India has stated that the issue of obesity has gone from 15 per cent in 2008 to 28 per cent in 2013 (Organisation for Economic Co-operation and Development (OECD), 2013). Proper nutritional education is needed for school going children as eating habits and behavior are formed from a young age and persist through adulthood (Kelder et al, 1994).

The main aim of Nutritional awareness is to make people aware of what constitutes a healthy diet and ways to improve their diets and their lifestyles. This can be done through different $\mathrm{ch}$ a n $\mathrm{n}$ el $\mathrm{s}$, although in general this occurs within schools targeting young children, since food habits in early stages of life are said to determine practices and preferences in adulthood" (Eat Well, 2011). 
Nutrition education in childhood can lead to building life-long healthy eating habits and help individuals cope with issues like malnutrition, diet-related chronic diseases, over-nutrition, deficiencies, under-nutrition, and obesity. It can also enable them to understand the positive impact of a healthy well-balanced diet, and identify the issues associated with diet and nutrition. Further, by ensuring their physical well-being, they can also gain a better control over their negative emotions like anger, depression, and frustration. For, nutrition education equips them with the right information and knowledge about 'comfort foods' that helps them minimize or curb these feelings (McNulty, 2013).

Nutritional awareness in adults is brought forth by employing techniques like food-based counselling, cooking demonstrations, and hands-on learning activities delivered by health workers and volunteers (UNICEF, 2012b). In children, media plays a key role in shaping the nutritional perceptions (Dorey \& McCool, 2009). Several active measures to provide nutritional education to school children are also taken by many global health organizations. For instance, FAO implements school gardening in many countries (FAO, 2005; FAO, 2010). Many child-centred NGOs are also working to incorporate health education into the curriculum of primary schools in several countries.

Save the Children, a leading humanitarian organization, has effectively employed the child-to-child method to deploy children to enthusiastically nurture health and nutrition in their communities (Save the Children, 2006). A program called McGovern-Dole Food for Education is funded by USDA. Part of this fund goes towards nutrition education (USDA, 2012). Many new programs have also been launched in the recent years to create a cohesive environment at schools for nutritional awareness.

When nutritional education programs are run in educational institutions like schools, pupils gain the right knowledge about the essential nutrients like carbohydrates, fats, proteins, minerals, vitamins, etc. They get to know the difference between healthy and unhealthy food items. They also become aware of the importance of diet and nutrition in their lives (Radhika, 2019).

\section{Role of Media and its Effectiveness in Creating Nutritional Awareness among School Students}

Unlike the recent times, mass media was believed to be harmful once. This was mainly because researchers and communication experts felt that the audience cannot really know the difference between fiction and nonfiction (Gunter, 2000). According to him, audience of media are naturally inept of reckoning alternative ways of viewing the world, and they resort to passively accepting media messages and hence forming a false consciousness about social reality (Adorno, 1991; Miller, 2000). It is true that media plays an important role in the lives of children, and is therefore a crucial factor that influences their nutrition-related beliefs and behaviors. Many studies have revealed that children spend a lot of time with different types of media like TV, internetbased media, etc. (Rideout et al., 2005; and Hancox et al., 2004).School students, especially adolescents, are at a developmental stage in which they have a better access to a wider range of media (Wakefield et al 2003). They also get pocket money and are able to have notable impact on household spending and consumption patterns (Dotson \& Hyatt, 2005). Marketers therefore target children through multiple mediums (Story \& French, 2004).

Marketers began targeting children only in the twentieth century when TV became a common place in households. In the recent years, due to the more people subscribing to TV channels which deliver childrenspecific programs, marketers have gained more opportunities to target children through advertising. These opportunities for marketers have been further by the internet. They employ different appealing advertising techniques like advergames (advertiser-sponsored video games created by companies for brand promotion), product discounts, video links, advertorials, and competitions to attract children (Moore, 2006). The use of such vigorous marketing strategies pushes the sales of micronutrient-poor foods, energy-dense foods, and fast foods (World Health Organization, 2003).Advertisements shape the beliefs pertaining to the normalcy and desirability of foods and other consumer goods. Food adverisements are highly effective in influencing food preferences and buying behavior, retaining brand loyalty, and getting new customers to share their experience (Ministry of Health, 2006).

Another major influence on school-going children is social media. A recent survey by Tata Consultancy Service (TCS) on Indian high school students in the age group of 12 to 18 years (studying in high school across 14 cities) says that $72 \%$ of them own a digital gadget or a smart phone, more than $50 \%$ of them have access to internet at home, and most of them spend an average of over 60 minutes on Social Media each day (Rai, 2017). They come across unhealthy food advertisements with funny animations, taglines, and cartoons. The peer acceptance of these visuals encourages the development of unhealthy eating habits (Center for Science in the 
Public Interest 2003). This social media influence also stimulates them to pressurize their parents to buy junk foods (Kelly et al. 2006; Coon \& Tucker, 2002; and Hitchings \& Moynihan, 1998).

Researchers agree that media is not the sole agent leading to the formation of eating habits. Individual perceptions and experiences also determine the impact and strength of the media messages- in promoting both healthy and unhealthy foods. However, there is no denial of the fact that media has an effect on their future heath, sometimes subtly, and sometimes more powerfully. Moreover, the potential of its negative effects are more than the positive ones (Brown \& Witherspoon, 2002; Wakefield et al., 2003).

Children's dietary beliefs, attitudes and behaviour are complex, and are determined by several factors like parental, cultural, environmental, psychological, and physiological influences (Birch \& Fisher, 1998). TV advertising alone, therefore, cannot be expected to completely influence children's dietaryattitudes, beliefs and behaviour. However, TV ads play a big influential role in these. The effectiveness of media in creating nutritional awareness among school students is discussed under two sections including theories supporting the influential role of media on children's nutritional awareness, and the type of food advertisements that children come across in media and their effect on their eating behaviour.

\section{Theories Supporting the Influential Role of Media on Children's Nutritional Awareness}

According to Cultivation theory, repeated exposure to persistent media themes and portrayals influences opinions in the direction of the media portrayals. For instance, if TV broadcasts present a higher violent crime rate than the existing situation in the society, heavy TV viewers are more likely to overrate the incidence of violence in the society and their own likelihood of getting involved in violence (Gerbner et al., 1994).

And according to Social cognitive theory (Bandura, 1994), children imbibe the behaviours symbolized in mass media and from the role models in their immediate social environment. Former studies have successfully applied this theory to nutrition interventions (Sahay et al, 2006), child overweight prevention interventions (Cole et al, 2006), and learning the environmental and individual consequences on youth eating behaviour (Story et al, 2002). As per these theories, it could be expected that children exposed to TV food ads will tend to develop perspectives and behaviours supporting the eating behaviour exhibited thereof.

\section{Food Advertisements that Children Come Across in Media and their Effect on Eating Behaviour}

Studies report that one in three ads broadcasted during children's TV viewing times are for food (Chapman et al, 2006; Neville et al, 2005; Zuppa etal, 2003). Most of these ads promote unhealthy foods like confectionery and drinks, sweetened breakfast cereals, and fast foods (Chapman et al, 2006; and World Health Organization, 2003). And none of these includes ads for fruit or vegetables (Gantz et al, 2007). Junk food brands spend a huge amount of money each year on advertising their products. These also use celebrity endorsements to prime perceptions that these foods are good for them (Hoek \&Gendall, 2006).

Using taste appeal to sell food products is also used largely in advertisements. These also include the appeal of contests, relate the products with fun, and, sometimes, emphasise on the product's 'newness'. Often ads relate their product with a physical activity and highlight the possible health benefits of consuming those. Many a times these stress the presence of 'essential nutrients' in the product (Gantz et al, 2007). Progressive exposure of children to TV food advertising fosters attitudes and beliefs supporting those foods vigorously presented in those. It develops positive attitudes in them towards junk foods including sweet drinks, confectionery, and fast foods. So, they end up consuming more of these junk in comparison to their counterparts who are not exposed to TV advertisements (Hoek \&Gendall, 2006).

The more the children were exposed to such advertisements, the more reinforced are their positive attitudes and eating behaviour toward junk foods. So, the overall TV viewing hours has a big influence on their pro-junk food attitudes and beliefs. In fact, studies have proven that the children's TV exposure is more firmly linked with food-related attitudes and beliefs than children's socio- demographic attributes like SES, grade, and gender (Dixon et al, 2007, and Coon \& Tucker, 2002).

Thus, unhealthy food ads on TV have a negative influence children's dietary behavior. Further, while watching TV children often resort to unhealthy snacking, which may not be the case when involved in other activities (Campbell \& Crawford, 2003; Vereecken et al, 2006; Coon \& Tucker, 2002). TV viewing also has a negative impact on energy intake and expenditure (Dietz \& Gortmaker, 2001). Additionally, media portrays junk food in a manner that paradoxically leads to both obsession with thinness and obesity. This irony poses trouble to adolescents, especially girls, when they are trying to get comfortable in their changing bodies (Story \& Faulkner, 
1990). Further, TV viewing also stimulates children to influence their parents' food buying decisions. A study showed that children's weekly TV viewing hours significantly corresponded with reported requests by them for the foods advertised and purchases by their parents of such foods (Taras et al 1989). The number of hours of TV viewing generated stronger connections with dietary beliefs and behaviour than the frequency of viewing TV commercials.

On the other hand, food ads supporting healthy foods are known to improve children's attitudes toward healthy food consumption. A study has found that this is true irrespective of whether or not healthy food ads were broadcasted along with unhealthy food ads. So, broadcasting more number of healthy food ads on children's TV may boost the appeal of these foods to children. The other way round is also true. However, the study also found some evidence that simultaneous broadcasting of junk food and healthy food ads triggered negative attitudes toward vegetables in children. But when the same number of healthy food ads was broadcasted without any junk food ads, children did not exhibit such negative behaviour.

Surprisingly, the broadcasting of healthy food ads along with junk food ads did not lower the influence of the junk food ads in encouraging unhealthy foods. The researchers believe that this may be due to the healthy food ads promoting alternatives to junk foods rather than directly opposing the chief messages in junk food ads (Dixon et al, 2007). Healthy food ads should derive inspiration from the ads that criticized the tobacco industry and disclosed their marketing tactics, and thus were successful in their mission of getting across their antismoking message to youth (Zucker et al., 2000).

Healthy food ads based on this advertising strategy may promote healthy foods and prevent the possible positive attitude toward junk food ads. For, kids already know that healthy foods are superior to junk foods, but depict less favourable attitudes to the former than the latter (Dixon et al, 2007). When it comes to social media messages related to eating habits, studies show that peer influence over those messages arise a conflict over parental influence. This results in adolescents resorting to junk foods, and declining to carry healthy food to school (McGinnis et al. 2006).

A study carried out in the Indian context states that the majority of adolescents eat healthy foods when they are at home. But on school days they tend to skip taking lunch boxes along with them to the school. Over 80 per cent respondents said that they buy their food at least once in a week during school days. Further, nearly 61 per cent of them ate out with friends at least once per week, and they often resorted to fast foods. The study proceeds to say that Indian adolescents show a positive response towards the health education provided by parents and the government. It also states that social media influences them to eat healthy foods and refrain from fast foods. The limitation of that study, however, was that it surveyed students from only some schools all over the country (Singh and Nayak, 2015).

\section{The Individual Perception of Students about Food Ads Presented in Media}

A study carried out to understand children's understanding of advertising reveals that children up to four years of age view ads as entertainment, children from six to seven years believe that these provide information, children from seven to eight years cannot differentiate between the intent to persuade and providing information, and children from ten to twelve years can comprehend aims and motives of advertising, but lack the ability to explain sales tactics (Kunkel et al, 2004). Children who are between Two to six years can identify accustomed brand names, characters, logos, and packaging. They can connect these with the products, particularly if the brands use features like cartoon characters, pictures, and bright colours. This recognition and awareness has been found to convert to nagging for particular brands and products even among very young children (Robinson, 2007). Adolescents, however, as shown by some studies, do not passively accept the messages presented in junk food ads. Rather, they actively develop their own unique representations of those (Jette et al, 2007; Wakefield et al., 2003; Kirkman, 2001).

A qualitative study on highly media literate adolescents showed that though media is a primary part of their lives, they did not highly value the health-promotion messages and nutritional info presented in the ads. Despite the ads presenting their products in an appealing manner and using promotional tactics like prizes and celebrity endorsements, the participants were uncertain or even suspicious about the message's credibility. They seemed to be highly conscious of being duped. Hence, they disengage, misinterpret, reinterpret, or distance themselves from the messages. Even then, effective advertising, promoting nutritious foods and eliminating junk foods on children's TV, would help normalize and reinforce healthy eating. It can also enable junk food eaters to recognize their eating behaviour as unhealthy and switch to healthy eating (Dorey \& McCool, 2009). 


\section{Ways in Which Media Can Create Nutritional Awareness among School Students}

The food and beverage industry argues that children should be taught media awareness instead of reducing ads, as they will be exposed to those in their adulthood anyway. However, though media literacy is useful, it does not account for bombarding children with ads promoting junk foods. Besides, exposure to ads or industry supported media literacy campaigns will not train children to be evaluative consumers (Watson et al, 2014). For, despite knowing the lack of truth and pervasive intent behind advertising, children request their parents for the products advertised (Mehta et al, 2010). Here are some ways in which media can create nutritional awareness among school students.

\section{A. Counter Advertising}

Till date, a lot of research has focused on the potential negative effects of junk food ads with comparatively little notice given to possible TV counter-advertising strategies for encouraging healthy eating among children (Dixon et al, 2007).Media research on other health problems shows that counter-advertising can be successful in encouraging healthy behaviour. Between 1967 and 1970, the US Federal Communications Commission, under the "Fairness Doctrine", made it mandatory for licensees who aired cigarette ads to give free media time for anti-smoking public service announcements. It was found that cigarette consumption in the United States drastically lowered during these years than during the period immediately before or afterwards, indicating the effectiveness of the anti- smoking campaign messages (Warner, 1985).If such a counter-advertising strategy should be applied to food ads, the commercial TV networks would need to air a higher number of healthy food ads than junk food ads, or broadcast "anti-junk food" ads that directly challenge the message presented by junk food ads (Dixon et al, 2007). This can generate the expected positive impact received by the anti-smoking campaign discussed above.

\section{B. Advertising Regulations}

In Ireland, a code called Irish code became operational since 4 June 2013. It bans celebrity endorsements and cartoon characters to promote unhealthy foods. And it makes it mandatory for such food ads to carry messages declaring the necessity of those products to be consumed in moderation as a part of a balanced diet (Broadcasting Authority of Ireland, 2013).In Finland, the Consumer Protection Act regulates the marketing to children. It prohibits ads that try to persuade children to purchase products through direct offers (Hawkes, 2004).

In Canada, the national public broadcaster- the Canadian Broadcasting Corporation, refrains from accepting ads in programs directed at children less than 12 years of age (Canadian Broadcasting Corporation, 2006).In France, in the year 2004, the public health legislation made it mandatory for TV and radio ads to include health information while advertising for beverages containing artificial sweeteners, added sugar or salt (BeverageDaily.com).The United States, in the year 2009, eliminated the tax deductibility of food advertising costs of marketing and ads directed at children to promote consumption of food of poor nutritional quality or of food at fast food restaurants (Kucinich, 2009).In India, the FSSAI recently banned selling low nutrition foods and drinks at school canteens and shops located within and nearby school premises (Sharma, 2019). It recommends making available healthy lunch menus and snacks at school canteens.

\section{Social Media Interventions}

In recent years, nutrition education interventions for young adults and adolescents are increasingly being carried out through social media (Yonker et al, 2015). This is because it is perceived that they are likely to be receptive when reached through these platforms for health (Perin, 2015).A review evaluated the effectiveness of social media interventions for improving nutritional literacy and dietary behaviours among adolescents and young adults in ethnically and racially diverse populations. It found the effectiveness of social media in this regard to be limited but promising. Of the sixteen researches it reviewed, it found eleven to have notable nutrition outcomes, indicating social media as a priceless tool for delivering interventions for young adults and adolescents. There were reductions in unhealthy habits, increases in healthy dietary behaviours, or improvements in clinical outcomes (Chau et al, 2018).

\section{Conclusion}

India has a largely heterogeneous population from various social strata who have different lifestyle and follow different eating habits. The need to provide nutritious food to children and the importance of a healthy body is emphasised by all but without proper understanding of what nutritional value the food actually contains. 
It is mandatory for children to know and understand what they eat, instead of just satisfying the hunger pangs with junk food. Awareness on this has to start from school as that is where children spend most of their active time engaging in active learning. More emphasis has to be given on the nutritional value the food contains and schools must ensure that children have sufficient knowledge of what they are eating and how it can either improve or affect their health.

\section{References}

1. Abler, A. (2008). Vision (Life and Health), Fostering Health and Nutrition Awareness in Children https://www.vision.org/fostering-health-and-nutritional-awareness-in-children-510.

2. Australian Divisions of General Practice. (2003). What are we feeding our children? A junk food advertising audit, Canberra.

3. Bandura, A. (1994). Social cognitive theory of mass communication. In J. Bryant, \& D. Zillman (Eds.), Media effects: Advances in theory and research, Hillsdale, NJ: Lawrence Erlbaum Associates, 61-90.

4. Broadcasting Authority of Ireland, BAI Issues Rules on Food Advertising to Children, 2020. https://www.bai.ie/en/bai-issues-rules-on-food-advertising-to-children/

5. Birch, L.L., \& Fisher, J.O. (1998). Development of eating behaviors among children and adolescents. Pediatrics, 101, 539-549.

6. BeverageDaily.com. (2004). France takes action on 'junk' food, alcopops. 2020. http://www.beveragedaily.com/Markets/France-takes-action-on-junk-food-alcopops

7. Chau, M.M., Burgermaster, M., \& Mamykina, L. (2018). The use of social media in nutrition interventions for adolescents and young adults-a systematic review. International Journal of Medical Informatics. https://doi.org/10.1016/j.ijmedinf.2018.10.001

8. Canadian Broadcasting Corporation. (2006). Advertising Directed to Children Under 12 Years of Age. https://cbc.radio-canada.ca/en/vision/governance/programming- policies/advertising/ads-children

9. Dixon, H.G., Scully, M.L., Wakefield, M.A., White, V.M., \& Crawford, D.A. (2007). The effects of television advertisements for junk food versus nutritious food on children's food attitudes and preferences. Social science \& medicine, 65(7), 1311-1323.

10. Eat, W. (2011). Review of policy actions, data available for their analysis and existing evaluations throughout Europe. Deliverable 1.1 of Eat Well for the European Commission. eatwellproject.eu/en/Eatwell-research/Project-Reports/

11. Moore, E. (2006). It's child's play: Advergaming and the online marketing of food to children, Kaiser Family Foundation. https://www.kff.org/other/its-childs-play-advergaming-and-the-online-2/

12. FAO. (2005). Setting up and running a school garden: A manual for teachers, parents and communities. Rome: Food and Agriculture Organization of the United Nations. ftp://ftp.fao.org/docrep/fao/012/a0218e/a0218e.pdf

13. FAO. (2011). Why nutrition education matters - Draft. Rome: Nutrition Education and Consumer Awareness Group, Food and Agriculture Organization of the United Nations.

14. FAO. (2012). Nutrition Education and Consumer Awareness - Professional Training in Nutrition Education. www.fao.org/ag/humannutrition/ nutrition education/69725/en/

15. Gerbner, G., Gross, L., Morgan, M., \& Signorielli, N. (1994). Growing up with television: The cultivation perspective. In J. Bryant, \& D. Zillman (Eds.), Media effects: Advances in theory and research, Hillsdale, NJ: Lawrence Erlbaum Associates, 17-42.

16. Rai, G. (2017). Impact of Social Networking Sites (SNSs): Are Youth affected by its usage?. Issues and Ideas in Education, 5(1), 11-24.

17. Hitchings, E., \& Moynihan, P.J. (1998). The relationship between television food advertisements recalled and actual foods consumed by children. Journal of Human Nutrition and Dietetics, 11, $511-517$

18. Kelder, S.H., Perry, C.L., Klepp, K.I., \& Lytle, L.L. (1994). Longitudinal tracking of adolescent smoking, physical activity and food choice behaviours. American Journal of Public Health, 84, $1121-1126$.

19. McNulty, J. (2013). Challenges and Issues in Nutrition Education. http://www.fao.org/3/i3234e/i3234e.pdf

20. Ofcom, HFSS advertising restrictions: final review, http://stakeholders.ofcom.org.uk/binaries/research/tv-research/hfss-review-final.pdf

21. Perrin, A. Social Media Usage: 2005-2015 [Internet]. Pew Research Center: Internet, Science \& Tech. 2015. http://www.pewinternet.org/2015/10/08/social- networking-usage-2005-2015/

22. Radhika, K. (2019). The Significance of Nutrition Education. ACTA Scientific, 3(10), 111-115.

23. Watts, R. Protecting children from unhealthy food marketing, 2007, British Heart Foundation and Children's Food Campaign. http://www.sustainweb.org/pdf/Protecting_Children_Report.pdf 
24. Representative Dennis Kucinich, H.R.4310-To amend the Internal Revenue Code of 1986 to protect children's health by denying any deduction for advertising and marketing directed at children to promote the consumption of food at fast food restaurants or of food of poor nutritional quality: referred to United States House of Representatives committee in December 2009.

25. Sahay, T., Ashbury, F., Roberts, M., \&Rootman, I. (2006). Effective components for nutrition interventions: A review and application of the literature. Health Promotion Practice, 7, 418-427.

26. Save the Children. 2006. Final Evaluation Report for USAID CS16 Project. dec.usaid.gov/dec

27. Robinson, T.N., Borzekowski, D.L., Matheson, D.M., \& Kraemer, H.C. (2007). Effects of fast food branding on young children's taste preferences. Archives of pediatrics \& adolescent medicine, 161(8), 792-797.

28. The Australian Food and Grocery Council website. https://aana.com.au/self-regulation/codesguidelines/australian-food-and-grocery-council- initiatives/

29. USDA. (2012). McGovern-Dole Food for Education and Child Nutrition Program. Available at: www.fas.usda.gov/excredits/foodaid/ffe/ffe.asp

30. Gantz, W., Schwartz, N., \& Angelini, J.R. (2007). Food for thought: television food advertising to children in the United States, Kaiser Family Foundation. http://www.kff.org/entmedia/upload/7618.pdf

31. Yonker, L. M., Zan, S., Scirica, C. V., Jethwani, K., \& Kinane, T. B. (2015). "Friending" teens: systematic review of social media in adolescent and young adult health care. Journal of medical Internet research, 17(1), e4. 